\title{
Selective removal of alleyway paper flooring or air to assess locus of nonreward odor
}

\author{
RONALD D. TAYLOR and H. WAYNE LUDVIGSON \\ Texas Christian University, Fort Worth, Texas 76129
}

\begin{abstract}
The locus of conspecific odors arising from nonrewarded trials administered to rats in a straight alleyway was examined by selectively removing odors from the alley air or paper flooring. Response patterning (discrimination) established with odors undisturbed on nonrewarded trials but removed from both the paper and the air on rewarded trials was diminished, but not eliminated, by removal of odors from either the paper or the air on nonrewarded trials. These data suggest that nonreward odor is present both on the paper and in the air. Additional manipulations designed to shed light on the role of odors present following both rewarded and nonrewarded trials indicate that, although odors arising from both rewarded and nonrewarded conspecifics can control patterned responding in this task, nonreward odor may exercise the greater control. This greater control by "nonreward odor" would seem to arise from its greater salience, as inferred from using magnitude of response patterning as an index of psychological similarity.
\end{abstract}

Studies concerned with the differential odor emissions of laboratory rats receiving rewarded and nonrewarded treatments have suggested that animal-related odors are present following both kinds of treatment (Collerain \& Ludvigson, 1977; Taylor \& Ludvigson, 1980). If rats are administered rewarded and nonrewarded trials in a straight alleyway and all animals are given the same reward event on a given trial, a pattern of fast running on rewarded trials and slow running on nonrewarded trials eventually emerges in the goal area (Ludvigson \& Sytsma, 1967). This patterned responding has been shown to be controlled by olfactory cues (e.g., Seago, Ludvigson, \& Remley, 1970). Although odors are present following both reward and nonreward, (e.g., Taylor \& Ludvigson, 1980), attention in the present study was focused only on odor following nonreward, termed "frustration odor" for convenience.

Of particular interest was where the odor resides after excretion. Although it is presumably in the air ${ }^{1}$ by the time it is utilized as a discriminative signal by the following subject, a question of considerable importance is whether it resides solely in the surrounding air space or on adjacent surfaces as well. The basis for this interest is at least twofold. First, the ability of this odor to serve as a cue raises concern about how one might eliminate it in order to avoid an unwanted bias. Second, knowing where the odor resides is a necessary first step toward collection, transfer, and chemical analysis of the substance.

Portions of this research were presented at the meeting of the Southwestern Psychological Association in New Orleans, Louisiana, 1978. Funding for the research was provided in part by a fellowship awarded to the first author by the Chemistry of Behavior Program and by the Texas Christian University Research Foundation. Requests for reprints should be sent to Ronald D. Taylor, who is now at the Department of Psychology, Salem College, Salem, West Virginia 26426.
McNeese (1975) found that patterned responding was maintained by replacing either the paper flooring or the alleyway air, thereby restricting the odor source to the air or to the surface, respectively. Those results implied that the odors were at least partially deposited on the flooring and that they vaporized rather rapidly. However, since these experimental operations were performed on all trials (both rewarded and nonrewarded) and it now appears that odor cues are present on both kinds of trials, the extent to which these conclusions apply solely to frustration odor is not clear. Since the interest of the present study was restricted to frustration odor, the paper on the floor and the air of the alley were separately replaced with clean paper and air on nonrewarded trials, and the effects of these operations on a discrimination based on frustration odor vs. a clean alley were observed.

\section{METHOD}

Subjects

The subjects were seven male albino rats used in a previous experiment (Taylor \& Ludvigson, 1980) in which alleyway odors were occasionally removed (i.e., both paper and air) on rewarded and/or nonrewarded trials. The subjects were 230 days of age on Day 1 and were maintained at $85 \%$ of their preexperimental ad-lib weights.
Apparatus
A straight alleyway equipped with an exhaust fan for replac- ing alley air and removable paper flooring served as the experi- mental apparatus. For details see Taylor and Ludvigson (1980).
Procedure
The rats received four rewarded and four nonrewarded trials each day by progressing through a repeated 4-day cycle of RNNRRRNN, RRNNNRRN, NRRNNNRR, and NNRRRNNR, where $R$ and $N$ represent reward and nonreward, respectively. The order in which the rats were run was constant on all trials, 
and all animals received the first trial before any animal received the second, and so on. Before a trial was administered to the squad of rats, the alleyway was cleaned by changing the paper flooring and exhausting the air for $60 \mathrm{sec}$. While a trial was being administered, the alleyway air and/or paper flooring were selectively replaced following each animal's nonrewarded goal experiences. On some days only the paper flooring or alley air was replaced on nonrewarded trials. Phase $A$, in which the patterned responding learned in the prior experiment was reestablished, involved leaving odors undisturbed on both $R$ and $\mathrm{N}$ trials $(\mathrm{R}+\mathrm{N}+)$. In Phase $\mathrm{B}$, both paper and air were replaced on $\mathrm{R}$ trials but neither was replaced on $\mathrm{N}$ trials $(\mathrm{R}-\mathrm{N}+)$. The latter phase provided a baseline against which to evaluate the effects of selectively replacing either paper or air on $\mathrm{N}$ trials. In Phase $\mathrm{C}, \mathrm{R}-\mathrm{N} \pm$, the paper was left undisturbed, but the air was replaced with room air after each animal on $\mathrm{N}$ trials, and both paper and air were replaced on $R$ trials. Phase $D$ was a return to baseline $(\mathrm{R}-\mathrm{N}+)$. In Phase $\mathrm{E}$, the paper was replaced after each animal on $\mathrm{N}$ trials, with the air left as undisturbed as possible, and both paper and air were replaced on $R$ trials $(\mathrm{R}-\mathrm{N} \mp)$. In Phase $\mathrm{F}(\mathrm{R}-\mathrm{N}-)$, both paper and air were replaced after each animal on both $R$ and $N$ trials in order to assess the effectiveness of the odor-removal procedures.

The last two phases of this experiment involved, first, returning to the $\mathrm{R}+\mathrm{N}+$ condition (Phase $\mathrm{G}$ ), followed by removing odors on nonrewarded trials only (Phase $\mathrm{H}, \mathrm{R}+\mathrm{N}-$ ). These manipulations were made in an attempt to replicate a previous finding reported by Taylor and Ludvigson (1980). In that study, shifting subjects from $\mathrm{R}+\mathrm{N}+$ to $\mathrm{R}+\mathrm{N}-$ resulted in a reversal in goal speeds, with subjects actually running faster on $\mathrm{N}$ trials than on $\mathbf{R}$ trials.

On rewarded trials, 20 45-mg Noyes pellets were dispensed after the animals interrupted the last photobeam, and $30 \mathrm{sec}$ were allowed for consuming the food. On nonrewarded trials, the animals were confined to the unbaited goalbox for $30 \mathrm{sec}$.

An intersubject interval of $3 \mathrm{~min}$ was maintained throughout the experiment. On all trials, each animal was carried in its home cage from a closed room to the experimental room and then taken to a third room following removal from the goalbox. A white-noise generator provided a constant background noise of about $85 \mathrm{~dB}$ in the experimental room throughout the experiment.

\section{RESULTS AND DISCUSSION}

The results of this experiment are presented in Figure 1. Treatments are represented at the bottom of the figure by the letters $\mathrm{R}$ and $\mathrm{N}$, each followed by a plus and/or minus sign, indicating that excreted odors were left undisturbed or removed, respectively.

Panel A of Figure 1, the R+N+ condition, simply shows that characteristic patterned responding, fast on rewarded trials and slow on nonrewarded trials, developed over trials during which the odors were undisturbed following both rewarded and nonrewarded treatments. As indicated previously, the subjects were quite experienced with the alleyway task; hence, there was some patterned responding present on Day 1 of this condition, and over the subsequent 4 days the magnitude of the discrimination achieved a level generally characteristic of $\mathrm{R}+\mathrm{N}+$ conditions.

\section{Baseline Discrimination Based on N Odors}

The first treatment, represented in Panel B of Figure 1 , involved replacing the paper and air after each

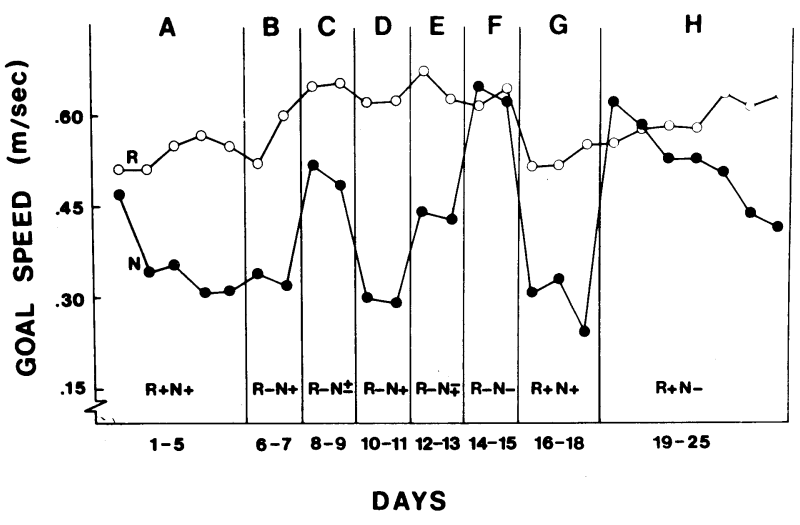

Figure 1. Mean daily goal speeds for rewarded (R) and nonrewarded (N) trials as a function of selective odor removal. (+ = paper flooring and alley air left undisturbed; - = paper flooring and alley air replaced with clean; $\pm=$ alley air removed only ; $\mp=$ paper flooring replaced with clean only.)

subject on rewarded trials. This treatment, $\mathrm{R}-\mathrm{N}+$, represents a baseline for the remaining treatments. Inspection of Figure 1 indicates that, consistent with previous results (Taylor \& Ludvigson, 1980), removal of odors on rewarded trials had little effect on patterned responding.

\section{Replacement of Air vs. Paper After N Trials}

Panel C of Figure 1 presents the $\mathrm{R}-\mathrm{N} \pm$ condition. During this phase, both paper and air were replaced with clean paper and air after each subject on rewarded trials, whereas on nonrewarded trials the paper flooring was left undisturbed but the air was replaced. Panel D represents a return to baseline in preparation for the treatment in Phase E. Panel E, $\mathrm{R}-\mathrm{N} \mp$, presents the results of replacing the paper flooring without replacing the air after each subject on nonrewarded trials and replacing both paper and air on rewarded trials.

For purposes of statistical analysis, goal speeds were averaged for the two baseline phases, Phases B and D, for each subject (excluding the first subject in the squad). An analysis of variance with treatments (Phases $B$ and D vs. Phase $C$ vs. Phase E) and goal events (R vs. $\mathrm{N})$ as repeated measures produced significant effects for goal events $[F(1,25)=309.12, \mathrm{p}<.001]$, treatments $[F(2,25)=36.77, p<.001]$, and the Goal Events by Treatments interaction $[\mathrm{F}(2,25)=12.74, \mathrm{p}<.001]$. Analysis of simple main effects indicated treatment differences for both rewarded $[\mathrm{F}(2,25)=5.39, \mathrm{p}<.05]$ and nonrewarded $[\mathrm{F}(2,25)=45.39, \mathrm{p}<.01]$ trials and $\mathrm{R}$ vs. $\mathrm{N}$ differences for the $\mathrm{R}-\mathrm{N}+, \mathrm{R}-\mathrm{N} \pm$, and $\mathrm{R}-\mathrm{N} \mp$ phases $[F s(1,25)=187.69,42.31$, and 111.54 , respectively; all ps $<.01]$. Follow-up with a Newman-Keuls test indicated that the subjects ran faster (1) on rewarded trials during the $\mathrm{R}-\mathrm{N} \pm$ and $\mathrm{R}-\mathrm{N} \mp$ treatments than during the $\mathrm{R}-\mathrm{N}+$ treatment (ps $<.05)$, (2) on nonrewarded trials during treatments $\mathrm{R}-\mathrm{N} \pm$ and $\mathrm{R}-\mathrm{N} \mp$ than during the $\mathrm{R}-\mathrm{N}+$ treatment (ps $<.01$ ), and (3) on nonrewarded trials during $\mathrm{R}-\mathrm{N} \pm$ than during $\mathrm{R}-\mathrm{N} \mp(\mathrm{p}<.05)$. 
These results indicate that replacement of either the paper or the air on nonrewarded trials produced a significant decrement in the magnitude of patterned responding without completely eliminating the discrimination. One interpretation of these data is that frustration odor was present both on the paper flooring and in the air. By this view, the patterning exhibited under Condition $\mathrm{R}-\mathrm{N} \pm$ could have occurred because the odor was sufficiently volatile to vaporize from the paper and reach an effective concentration in the air within $30 \mathrm{sec}$ (the approximate time between switching off the exhaust and placing the next subject into the startbox). ${ }^{2}$ The fact that goal speeds on nonrewarded trials were slower when the paper was removed $(\mathrm{R}-\mathrm{N} \mp)$ than when the air was removed $(\mathrm{R}-\mathrm{N} \pm$ ) could reflect differences in the concentration of the odor resulting from these treatments. On the other hand, this difference might be attributable to an increased sensitivity to small quantities of frustration odor as the experiment progressed, since air removal preceded paper removal.

The faster goal speeds on rewarded trials during Phases C and E relative to the mean of Phases B and D could be attributed to the relatively slow speeds during Phase B. Since Taylor and Ludvigson (1980) demonstrated that a shift from $\mathrm{R}+\mathrm{N}+$ to $\mathrm{R}-\mathrm{N}+$ is accompanied by increases in goal speeds on rewarded trials, Phase $B$ may reflect the beginning of such a trend, whereas Phases C-E may represent values approaching asymptote.

\section{Test of Odor-Removal Procedures}

The data from a final test of the effectiveness of our odor-removal procedures are presented in Panel $F$ of Figure 1. A t test comparing goal speeds on rewarded and nonrewarded trials during this phase was nonsignificant $(t<1)$. Judging from the overlapping curves, there appears to have been adequate control of the olfactory stimuli, such that when both paper and air were replaced, discrimination was eliminated.

\section{Removal of N Odors}

A return to $\mathrm{R}+\mathrm{N}+$ conditions (see Figure 1, Panel G) was instituted to replicate the effects observed when subjects were shifted from $\mathrm{R}+\mathrm{N}+$ to $\mathrm{R}+\mathrm{N}-$ (Taylor \& Ludvigson, 1980). In Phase $H$, the reversal of $R$ and $N$ speeds occurred on Day 1 of the $\mathrm{R}+\mathrm{N}$ - treatment; a $t$ test comparing these speeds on this day found the difference to be nonsignificant $[t(5)=2.39, p<.05$, two-tailed test]. However, combining this result with the similar result from the Taylor and Ludvigson (1980) study in a combined-probabilities test (Winer, 1971) yielded $\chi^{2}(4)=13.69(p<.01)$, indicating that these two reversals were not likely products of chance. A test over the last 2 days of this phase confirmed that the discrimination between reward odor and a clean alley was reestablished $[t(5)=4.16, p<.01]$. The results were consistent with the previous data, indicating the presence of an odor on rewarded trials. It may be noted that since all pellets were dispensed after a subject had traversed the alley, the smell of food in the goal cup could not have been the discriminative cue on rewarded trials.

\section{Odor Similarity}

Although incidental to their main purposes, these data, taken together with those reported by Taylor and Ludvigson (1980), contribute to a rough characterization of the psychological similarities or distances among reward odor, frustration odor, and a clean or no-odor condition. The rank order of these distances, inferred on the bases of certain aspects of the data, then permits a further understanding or assimilation of certain other aspects of the data. For convenience, in the following discussion, Experiment 1 will be used to refer to the data reported previously (i.e., Taylor \& Ludvigson, 1980) and Experiment 2 will refer to the data in the present report. Taking the magnitude of terminal response patterning (i.e., the difference between $R$ and $\mathrm{N}$ speeds) in a phase of testing as an index of psychological distance, one can estimate, relatively, the distances between (1) reward odor and the clean condition, (2) frustration odor and the clean condition, and (3) reward odor and frustration odor. ${ }^{3}$ Table 1 presents these response-patterning magnitudes, based on the last day of a phase, together with the phases in the two experiments from which they arise. These differences suggest, first, that frustration odor is more distant from a clean condition than is reward odor, or to use a concept of much currency, frustration odor is more salient than reward odor under the conditions of these studies. This inference arises simply from the observation that difference $f-c$ is greater than difference $r-c$. Second, if the ranking of the three differences reliably reflects the ranking of the psychological distances involved, then reward odor lies "between" frustration odor and clean, in that the distance $r-f$ is less than the distance $f-c$.

Table 1

Speed Differences (in Meters per Second) Between R and N Goal Speeds on the Last Day of Phases Providing Estimates of the

Psychological Distance Between Reward Odor and Clean $(r-c)$, Frustration Odor and Clean $(f-c)$, or Reward Odor and Frustration Odor $(r-c)$

\begin{tabular}{llll}
\hline & \multicolumn{3}{c}{ Distance Estimated } \\
\cline { 2 - 4 } Experiment & $\mathrm{r}-\mathrm{c}$ & $\mathrm{f}-\mathrm{c}$ & $\mathrm{r}-\mathrm{f}$ \\
\hline \multirow{2}{*}{1} & & & $.24(\mathrm{~A})$ \\
& $.19(\mathrm{~F})$ & $.36(\mathrm{D})$ & $.25(\mathrm{C})$ \\
2 & & & $.17(\mathrm{E})$ \\
& & $.28(\mathrm{~B})$ & $.23(\mathrm{~A})$ \\
Mean & $.22(\mathrm{H})$ & $.33(\mathrm{D})$ & $.31(\mathrm{G})$ \\
Rank & .205 & .323 & .240 \\
& 3 & 1 & 2 \\
\hline
\end{tabular}

Note-Experiment 1 refers to Taylor and Ludvigson (1980). Phases providing the differences are indicated in parentheses. 
Given these simple relationships, the greater effect produced by removal of frustration odor compared with reward odor may be interpreted. Assume that excitation and inhibition accrue to reinforced and nonreinforced stimuli, respectively, and that these response tendencies generalize to other stimuli as a function of psychological distance. Then removal of reward odor (in Phase D of Experiment 1, Phases B and D of Experiment 2), an operation that actually replaces reward odor with the clean condition, should leave an inhibitory frustration odor and a clean condition that receives more generalized excitation from the reward-odor stimulus than generalized inhibition from frustration odor. With these conditions present, one would not expect responding to be greatly disrupted. On the other hand, removal of frustration odor (in Phases $\mathrm{F}$ and $\mathrm{H}$ of Experiments 1 and 2 , respectively) should leave an excitatory reward odor and a clean condition to which mostly generalized excitation accrues. In this case patterning should be greatly disrupted, as it was immediately after this change in stimuli. In fact, given the ranking of distances in Table 1, the greater response strength to the clean condition than to the reward odor on these days (Days 13 and 19 in Experiments 1 and 2, respectively) is interpretable as a peak shift in the generalization function (e.g., Mackintosh, 1974). That is, it is frequently reported that, compared with response strength associated with the rewarded stimulus, more response strength accrues to some stimuli more distant from the inhibitory stimulus. In the present case, clean is more distant from frustration odor than is reward odor. This peak-shift analysis also fits with the observation that speeds to clean odor during phases in which it is being consistently rewarded (Phase D in Experiment 1, Phases B-E in Experiment 2) tend to be faster overall than speeds to reward odor (Phases A, C, E, and F in Experiment 1; Phases A, G, and $\mathrm{H}$ in Experiment 2). However, no peak shift is seen in Phase B of Experiment 1 or immediately in Phase B of Experiment 2, for reasons that are not clear.

Finally, employing this generalization-along-distances hypothesis, the fact that removal of odor on both $\mathrm{R}$ and $\mathrm{N}$ trials sometimes results in an immediate increase in $\mathrm{N}$ speed and other times in an immediate decrease in $\mathrm{R}$ speed may be addressed. In Phase $F$ of Experiment 2, clean had just been (in Phase E) associated with reward, which should have made it excitatory; thus the elevated $\mathrm{N}$ speed to clean in this phase would be expected. Similarly, in Phase B of Experiment 1, reward odor had just been associated with reward (in Phase A), so that clean should also have been excitatory by virtue of its proximity to reward odor. In contrast, in Phase $G$ of Experiment 1, prior treatment (in Phase F) had associated clean with nonreward, making it inhibitory; thus in Phase G, clean would be expected to produce lowered response strength on the first shift trials, as it did.

\section{REFERENCES}

Collerain, I., \& Ludvigson, H. W. Hurdle-jump responding in the rat as a function of conspecific odor of reward and nonreward. Animal Learning \& Behavior, 1977, 5, 177-183.

Eslinger, P. J. The question of constraints on learned responses to odors from rewarded and nonrewarded rats: Effects of goal events opposite to those engendering odor. Unpublished master's thesis, Texas Christian University, 1978.

Ludvigson, H. W., \& Sytsma, D. The sweet smell of success: Apparent double alternation in the rat. Psychonomic Science, $1967,9,283-284$.

Mackintosh, N. J. The psychology of animal learning. London: Academic Press, 1974.

MCNEESE, R. R. The effects of gonadectomy on the production, avoidance, and discrimination of frustration odor. Unpublished master's thesis, Texas Christian University, 1975.

Seago, J. D., Ludvigson, H. W., \& Remley, N. R. Effects of anosmia on apparent double alternation in the rat. Journal of Comparative and Physiological Psychology, 1970, 71, 435-442.

TAYLOR, R. D., \& Ludvigson, H. W. Selective removal of reward and nonreward odors to assess their control of patterned respording in rats. Bulletin of the Psychonomic Society, 1980, 16, 101-104.

Winer, B. J. Statistical principles in experimental design. New York: McGraw-Hill, 1971.

\section{NOTES}

1. Various studies suggest it is a rather volatile substance, although the possibility cannot be ruled out that at least some of its components are of low volatility and stimulants for the vomeronasal organ.

2. Alternatively, frustration odor could comprise separate high-volatile and low-volatile components stimulating, respectively, the olfactory epithelium and the vomeronasal organ.

3. Using these terminal response levels as measures of psychological distance assumes the absence of "response biases." That is, since the experimental procedure did not permit using frustration odor as a signal for reward or using reward odor as a signal for nonreward, one must assume that the distances do not critically depend on whether reward or frustration odor is used as the cue for reward. This assumption is reasonable in light of recent data from our laboratory showing that small initial biases (e.g., perhaps an "avoidance" of frustration odor) rather quickly habituate (Eslinger, 1978).

(Received for publication June 12, 1980.) 